\title{
RARE CASE OF CERVICAL LIPOLEIOMYOMA
}

Vijay Kalyankar' ${ }^{1}$ Bhakti Kalyankar²

\section{HOW TO CITE THIS ARTICLE:}

Vijay Kalyankar, Bhakti Kalyankar. "Rare Case of Cervical Lipoleiomyoma". Journal of Evolution of Medical and Dental Sciences 2014; Vol. 3, Issue 20, May 19; Page: 5529-5533, DOI: 10.14260/jemds/2014/2624

INTRODUCTION: Surgery is like hunting, if you are going for a rabbit, be ready to face a tiger. Abdomen is like a magic box, clinicians suspect one thing, radiologists conclude other thing and surgeons surprise us by extracting something else.

CASE REPORT: A 35 years old ${ }^{1,2}$ female, Para 3 Living 3 with tubectomy done 12 years back having all full term vaginal deliveries came with chief complaints of pain in abdomen and discomfort in vagina since 4 months. There was no history of any menstrual or bowel, bladder complaints. General and systemic examinations were within normal limits. On per abdominal examination liver and spleen were not palpable, umbilicus was in normal position, and there was a firm mass arising from pelvis about 18 weeks' pregnancy size, mobile, non-tender, no evidence of ascites.

On per speculum examination, cervix was taken up and not visualized. There was bogginess in posterior fornix of vagina. On per vaginal examination, cervix was pin-point; retro pubic and taken up, about 18 weeks' pregnancy size mass was felt. The movements of mass were transmitted to cervix; uterus could not be made out separately.

Her lab profile values were within normal limits with hemoglobin 10.5 gm\%. On ultrasonography findings ${ }^{3}$ there was huge isoechoic mass of size $112 \times 80$ millimeters occupying right pelvic region and extending upwards probably arising from right ovary, uterus normal, and left ovary normal- findings suggestive of ? Right ovarian dermoid. ${ }^{4}$

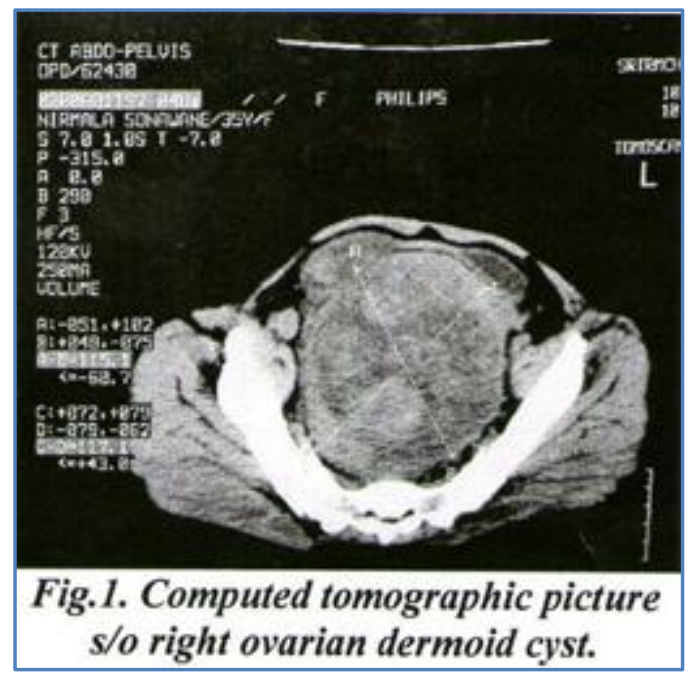

On computed tomography, right ovary showed well defined circular lesion of $115 \times 105$ millimeter with regular borders without calcification, uterus- normal, left ovary- normal-findings suggestive of right Ovarian Dermoid Cyst. 4 


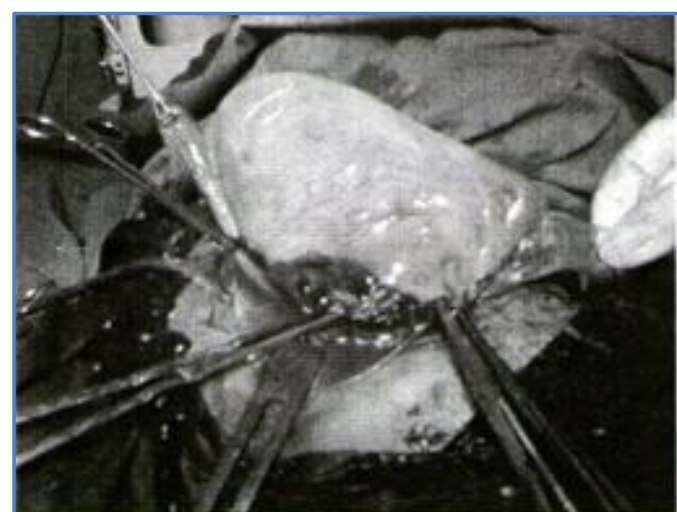

Fig.2. Intra-operative view of Huge Cervical Fibroid.

With enough blood reserved, we opened the abdomen in layers and tried to palpate and deliver out the mass, but it was very difficult to deliver and surprisingly both ovaries, both fallopian tubes and uterus were normal. For proper visualization of mass, we opened out anterior and posterior folds of right sided broad ligament. ${ }^{5}$ Both the round ligaments were visualized, clamped and ligated. Anterior peritoneal fold was opened at the level of round ligaments and urinary bladder overlying in front of mass was dissected downwards.5, 6

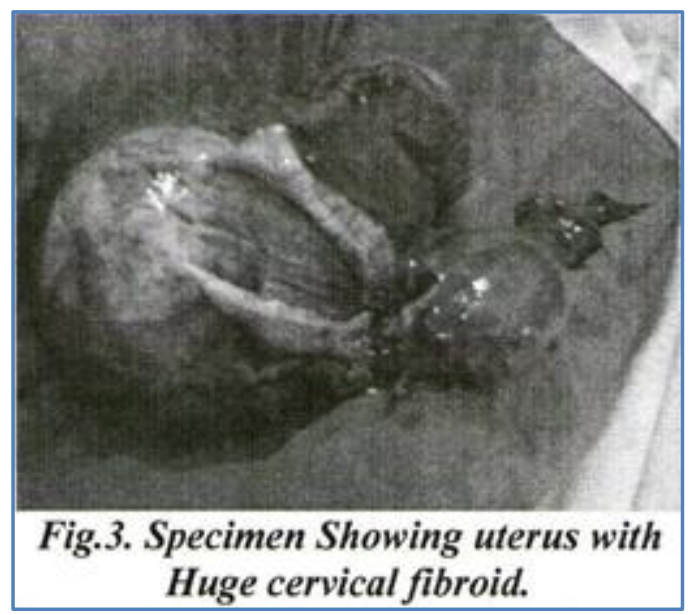

Peritoneum over anterior surface of supra vaginal cervix was reflected by inserting finger, exact plane of separation between tumor and capsule was defined. We tried to separate the mass from surrounding structures by giving gentle pull over the tumor.[5] Uterine vessels on both sides were brought into view, clamped, cut and ligated. Complete hemostasis was achieved.

As mass was encroaching pelvic cavity posteriorly, it was very difficult to define retro peritoneal structures like ureters and iliac vessels before removing the mass. The mass showed an elongated pedicle like structure which on bimanual examination surprised to be cervix. By applying Allie's Forceps, curvilinear incision was taken just below the elongated cervix. Vault was opened and specimen delivered out.

The mass was arising from posterior aspect of cervix and was posterior cervical fibroid of 150 x 130 millimeter dimensions with cervical elongation. All important structures like ureters and iliac vessels were obscured before removal of mass. Here, along with removal of cervical fibroid, we did 


\section{CASE REPORT}

hysterectomy with right sided salpingo-oophorectomy. Specimen was sent for histopathological examination. Intraoperative urine output was 500 cubic centimeter, clear and approximate blood loss was 800 cubic centimeter. We gave 2 units of blood transfusion and her postoperative recovery was satisfactory and she was discharged on day $8^{\text {th }}$ uneventfully. ${ }^{6}$

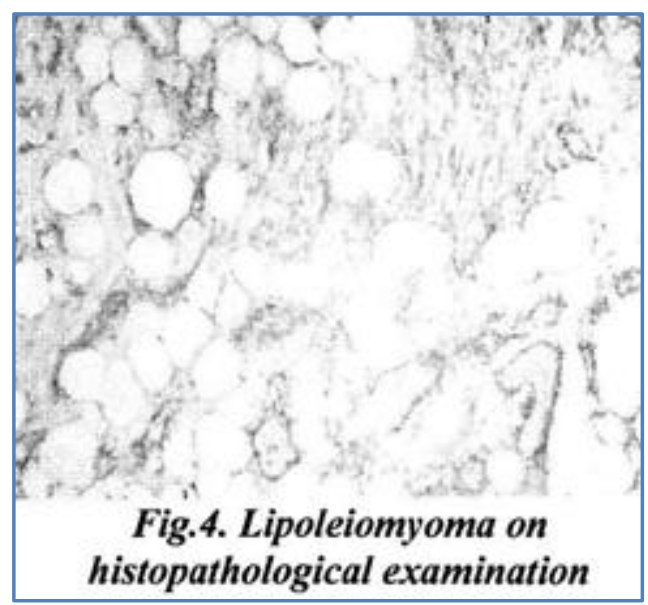

On histopathological examination again we got rare findings suggestive of Lipoleiomyoma. Pathology revealed admixture of mature adipose tissues and smooth muscles with hyaline degeneration. ${ }^{7}$

DISCUSSION: Cervical fibroid constitutes $1-2 \%$ of total fibroids with 3 types- interstitial, supravaginal and polypoidal. No menstrual disorder occurs in Cervical Fibroid but symptoms are predominantly due to pressure effect on surrounding structures like urinary symptoms (retention and frequency) and rectal symptoms (constipation) or maybe asymptomatic. Cervical Fibroid with excessive growth causes upward displacement of uterus and the fibroid may become impacted in pelvis causing urinary retention and ureteric obstruction. ${ }^{6}$

Cervical Fibroid gives rise to greater surgical difficulty by virtue of their relative inaccessibility and close proximity to urinary bladder and uterus. ${ }^{6}$ Interstitial growth may displace cervix or expand it so much that external os is difficult to recognize. Disturbed anatomy of ureter is a matter of concern for us.

While operating, surgeon has to pass his finger all around the tumor, separating fibroid away from adherent fascia and simultaneously pushing ureter away from fibroid. Fibroid is such that it pushes uterus towards unaffected side and vessels and ligaments on the healthy side are difficult to access. In such situations, the only option is to proceed with hysterectomy from one side of fibroid. Ascertaining correct plane of cleavage between capsule and tumor is very important.

Lipoleiomyomas are rare benign tumors with reported incidence of $0.03 \%$ to $0.2 \% .{ }^{5}$ Most of the reported cases of Lipoleiomyoma have been retrospectively diagnosed after surgery, with some being pre-operatively misdiagnosed as ovarian teratomas. ${ }^{2,8}$

The pathogenesis of this benign tumor is unknown with explanations including a tumor arising from misplaced embryonic remains of lipoblast, perivascular extension of peritoneal and retro-peritoneal fat, neometaplasia of lipomatous component derived from immature perivascular cells, lipolytic differentiation of primitive connective or mesenchymal tissue or fatty metamorphosis 
of smooth muscle cells or connective tissue into adipose cells, ${ }^{2}$ this is most widely accepted mechanism underlying the development of Lipoleiomyoma. The signs and symptoms produced by Lipoleiomyoma, diagnosis and management are similar to that of leiomyoma.

\section{CONCLUSION:}

1. Big fibroid may manifest without pain, classical symptoms of menorrhagia and infertility.

2. Computed Tomography and Abdominal Ultra Sonography may not always help in defining the true pathology; therefore surgeons should be mentally prepared to face the unexpected. It also emphasizes the importance of clinical examination.

3. Surgical dissection is to be completely achieved after defining proper anatomy.

4. Blood loss is minimized, if dissection is done in right plane of fibroids.

5. Stepwise dissection of difficult fibroids with cool mind is highly necessary.

6. Gynecological surgeons may not be very well acquainted to retroperitoneal structures. So, the help of surgeons should be taken without hesitation.

7. A perusal of English literature revealed only approximately 140 cases of Lipoleiomyoma. ${ }^{9}$ This rare case presented at 35 years of age when the mean and median age are 54 and 51 respectively. ${ }^{1}$ Lipoleiomyoma was at cervix. This could add to further rarity to this case. Otherwise, this tumour is located in $83 \%$ of the cases in uterine corpus. ${ }^{1}$

\section{REFERENCES:}

1. Wang X, Kumar D, Seidman JD. Uterine Lipoleiomyomas - A clinicopathologic study of 50 cases. Int J Gynecol Pathology 2006 July; 25(3); 239-242.

2. Singh R, Bipin Kumar, Bhat R V, Dorairajan G. Uterine Lipoleiomyoma: A report of 2 cases with a brief review of Literature. J of Clinical and Diagnostic Research 2012: May, vol 6, issue4, 718719.

3. Venkatanarsimha N, Dubbins PA, Freeman SJ. Incidental Uterine Mass. Br J of Radiology (2009) 82:1043-1045.

4. Su WH, Wang PH, Chang SP, Su MC. Preoperative diagnosis of uterine Lipoleiomyomas using ultrasonography and CT images, a case report. Eur J Gynaecol Oncol, 2001; 22(6); 439-440.

5. M Sami Walid, Heaton RL. A case report of Cervical Lipoleiomyoma. GMS German Medical Science - 2010; DOC 26; ISSN- 1612- 3174.

6. Basnet N, Banerjee B, Badani U, Tiwari A, Raina A, Pokharel H, Yadav P, Agrawal A, Chhetri S. An unusual presentation of huge cervical fibroid. Kathmandu University Medical Journal (2005) Vol. 3, No. 2, Issue 10, 173-174.

7. Manjumatha HK, Ramaswamy A.S, Bylappa Sunil K. Lipoleiomyoma of Uterus in Postmenopausal woman. J Midlife Health 2010 July-Dec 1(2): 86-88.

8. Sudhamani S, Agrawal D, Pandit A, Kiri VM. Lipoleiomyoma of Uterus; A case report with review of Literature. Ind J of Pathology and Microbiology - 2010; 53; 4, 840-841.

9. Terada T. Ovarian malignant Mullerian mixed tumor (heterologous) whose epithelial component is composed predominantly of signet ring cell carcinoma. Arch Gynecol Obstet.2011; 283:1403-1406. [PubMed]. 


\section{CASE REPORT}

\section{AUTHORS:}

1. Vijay Kalyankar

2. Bhakti Kalyankar

\section{PARTICULARS OF CONTRIBUTORS:}

1. Associate Professor, Department of Obstetrics and Gynaecology, Swami Ramanand Teerth Rural Government Medical College, Ambajogai.

2. Associate Professor, Department of Obstetrics and Gynaecology, Government Medical College, Aurangabad.

\section{NAME ADDRESS EMAIL ID OF THE} CORRESPONDING AUTHOR:

Dr. Vijay Kalyankar,

Associate Professor,

Department of Obstetrics and Gynaecology, Government Medical College,

Aurangabad.

Email: vijukalyankar@rediffmail.com

Date of Submission: 14/05/2014.

Date of Peer Review: 15/05/2014.

Date of Acceptance: 17/05/2014.

Date of Publishing: 19/05/2014. 